\title{
Three functional mutation sites affect the immune response of pigs through altering the expression pattern and IgV domain of the CD4 protein
}

Weiya Zhang ${ }^{1 \dagger}$, Juan $\mathrm{Ni}^{2,3+}$, Jie Zhang ${ }^{4}$, Lu Zhang ${ }^{4}$, Huanhuan Zhou ${ }^{4}$, Changzhi Zhao ${ }^{4}$, Mengjin Zhu ${ }^{4}$, Haiyan Wang ${ }^{4}$, Jianlin $\mathrm{Han}^{5}$, Xinyun $\mathrm{Li}^{4,6^{*}}$ and Shuhong Zhao ${ }^{4,6^{*}}$

\begin{abstract}
Background: The CD4 protein is an important surface marker of T lymphocytes, which can mediate the antigen presentation process by interacting with MHC II and TCR molecules in human and mouse.

Results: In this study, two haplotypes (A and B) of the CD4 gene were found within Chinese indigenous and Western commercial pig breeds. These two haplotypes were defined by 22 fully linked SNPs in the CDS region of the CD4 gene. The expression level and localization of the CD4 protein were significantly different between haplotypes A and B. Transcriptome analysis revealed that the immune response-related genes and signaling pathways were down-regulated in genotype AA. Finally, three linked functional SNPs were identified, which affected the expression level and membrane localization of the CD4 protein in pigs. These three SNPs led to the replacements of two amino acids in the lgV1 domain of the CD4 protein, and related to the function of the CD4 protein in the immune response.

Conclusion: These three linked SNPs were the key functional mutation sites in the CD4 gene, which played important roles in the immune response, and could be utilized as new molecular markers in breeding for disease resistance in pigs.
\end{abstract}

Keywords: Functional mutations, CD4 gene, Translation, Membrane localization, Immune response, Pig

\section{Background}

The CD4 molecule belongs to a class of differentiation antigens expressed on the surface of immune responserelated cell, such as $\mathrm{T}$ cells $[1,2]$. $\mathrm{T}$ cells play a vital role in anti-pathogen infection, autoimmune disease, and antitumor immunity. Based on the expressions of the

\footnotetext{
*Correspondence: xyli@mail.hzau.edu.cn; shzhao@mail.hzau.edu.cn

${ }^{+}$Weiya Zhang and Juan Ni contributed equally to this work.

${ }^{4}$ Key Laboratory of Agricultural Animal Genetics, Breeding, and Reproduction of the Ministry of Education, Swine Genetics and Breeding of Ministry of Agriculture and Rural Affairs, Huazhong Agricultural University, No.1 Shizishan Street, Hongshan District, Wuhan, Hubei Province 430070, P. R. China Full list of author information is available at the end of the article
}

surface makers of CD4 and CD8, T cells possess four developmental stages. The first stage contains the most immature thymocytes with double negative (DN) CD4 and $\mathrm{CD} 8$. The second stage is characterized by up-regulation of both CD4 and CD8, producing double-positive (DP) thymocytes. The third stage contains CD8 or CD4 single-positive (SP) thymocytes via positive selection of MHC I or II molecules [3]. $\mathrm{CD}_{4}{ }^{+} \mathrm{T}$ cells eliminate pathogens by helping innate immune responses, $\mathrm{B}$ cells, and $\mathrm{CD}_{8}{ }^{+} \mathrm{T}$ cells. Moreover, cytotoxic $\mathrm{CD} 4^{+} \mathrm{T}$ cells $\left(\mathrm{CD}_{4}{ }^{+}\right.$ CTLs) can directly induce the apoptosis of target cells that have overexpressed MHC II due to viral infection

C C The Author(s). 2020 Open Access This article is licensed under a Creative Commons Attribution 4.0 International License, which permits use, sharing, adaptation, distribution and reproduction in any medium or format, as long as you give appropriate credit to the original author(s) and the source, provide a link to the Creative Commons licence, and indicate if changes were made. The images or other third party material in this article are included in the article's Creative Commons licence, unless indicated otherwise in a credit line to the material. If material is not included in the article's Creative Commons licence and your intended use is not permitted by statutory regulation or exceeds the permitted use, you will need to obtain permission directly from the copyright holder. To view a copy of this licence, visit http://creativecommons.org/licenses/by/4.0/ The Creative Commons Public Domain Dedication waiver (http://creativecommons.org/publicdomain/zero/1.0/) applies to the data made available in this article, unless otherwise stated in a credit line to the data. 
[4]. In addition, the $C D 4$ gene plays an important role in $\mathrm{T}$ cell development. In humans, the CD4 protein contains four Ig-like extracellular domains, one transmembrane domain, and a C-terminal cytoplasmic tail [5-7]. The expression level of the CD4 protein corresponds to cell lineages with different specific functions during $\mathrm{T}$ cell development. Therefore, the regulation of the CD4 protein level is linked to developing $\mathrm{T}$ cells.

Previous studies indicated that the expression level of the $C D 4$ gene was strictly controlled by five stagespecific cis-elements, which included silencer (S4), proximal enhancer (E4p), distal enhancer, thymocyte enhancer, and intronic enhancer. Among them, E4p was required to maintain a stable level of $C D 4$ gene expression during positive selection in DP thymocytes, S4 repressed the expression level of the $C D 4$ gene in $\mathrm{DN}$ and cytotoxic $\mathrm{CD}_{8}{ }^{+} \mathrm{T}$ cells, and $\mathrm{E} 4 \mathrm{~m}$ promoted the expression level of the $C D 4$ gene in post-selected stages [8]. Moreover, five transcription factors regulated the expression level of the $C D 4$ gene by binding to ciselements during $\mathrm{T}$ cell development, which included Runx1, Runx3, HEB, TCF1, and E2A [9]. In addition, the activity of $\mathrm{T}$ helper cells was reduced due to the production of Il-2 in CD4 knockout mice [10].

CD4 can mediate the antigen presentation process by interacting with MHC II and the TCR signaling pathway. The inhibition of CD4-MHC II interaction weakened the immune response of $\mathrm{T}$ cells to exposed antigen, and the reduction in the expression level of the $\mathrm{CD} 4$ protein impaired signal transduction of the TCR pathway in T lymphocytes of mice [11]. Moreover, the ability to resist Leishmania infection was impaired in CD4 knockout mice [10].

Some mutations in the CD4 gene are related to immune diseases or viral infection. In humans, three SNPs in the promoter region of the $C D 4$ gene were related to type 1 diabetes mellitus [12]. A trait-association study indicated the relationship of two SNPs in the enhancer regions to the severity of rheumatoid arthritis [13]. Furthermore, one $\mathrm{C}$ to $\mathrm{T}$ substitution at nucleotide position 868 of the CD4 gene was related to HIV-1 acquisition and disease progression in Kenyans [14-16]. In macaques, one amino acid replacement at position 39 of the $\mathrm{CD} 4$ protein was responsible for restricting HIV infection [17]. Matsubara et al. found that there were two haplotypes (CD4.A\&CD 4.b) in the full-length of CD4CDS in Japanese miniature pigs, and CD4 protein encoded by these two haplotypes showed different binding capacities to CD4 antibodies due to the amino-acid substitutions [18]. Nevertheless, the functional mutation sites of the $C D 4$ gene in swine are largely unknown.

In this study, 22 fully linked SNPs in the CDS region of the CD4 gene were identified in F2 population of Duroc $\times$ Erhualian, which led to the formation of two haplotypes. Moreover, the expression level, membrane localization, and the immune responses of the CD4 protein were different between different haplotypes. Finally, the key mutation sites that led to functional differences between two haplotypes were identified. This study offers an important marker for regulating the immune response of pigs, and this molecular marker can be used in breeding for disease resistance in pigs.

\section{Results}

Fully linked SNPs in the CDS region led to the formation of two haplotypes of the CD4 gene

To identify the haplotypes of the $C D 4$ gene in pigs, blood samples from 22 pigs were obtained for amplification and sequencing analysis of the CD4 gene. In total, 22 SNPs in the CDS region were identified, which were linked completely and led to the formation of two haplotypes of the $\mathrm{CD} 4$ gene (haplotypes A and B). Among them, 16 SNPs resulted in amino acid replacement (Fig. 1a). To investigate the functional differences of different haplotypes of the CD4 gene, we examined the variable splicing of the $C D 4$ gene. The results showed that six transcripts could be formed by variable splicing, named CD4fl (full length), CD4 $\Delta 4$ (exon 4 deletion), $\mathrm{CD} 4 \Delta 8$ (exon 8 deletion), CD4 $\Delta 4 \Delta 8$ (exon 4 and 8 deletion), CD4 $\Delta 44^{\prime} \Delta 5^{\prime}$ (partial deletion of both exons 4 and 5), and CD $4 \Delta 4^{\prime} \Delta 5^{\prime} \Delta 8$ (partial deletion of exons 4 and 5, and total deletion of exon 8) (Fig. 1b). Furthermore, the abundance of the specific transcripts in haplotype A and $B$ was analyzed. 514 single clones of the CDS fragment from three $A B$ heterozygotes were selected randomly for sequencing. This result showed that $\mathrm{CD} 4 \mathrm{fl}$ and $\mathrm{CD} 4 \Delta 8$ were the transcripts in highest abundance. Moreover, the proportion of CD4fl in haplotype A was significantly lower than in haplotype B $(0.49 \pm 0.02$ vs. $0.61 \pm 0.01$, $P<0.05)$, and the proportion of $C D 4 \Delta 4 \Delta 8$ was higher in haplotype A than in $\mathrm{B}(P<0.07)$. However, the CD4 $\Delta 4$ transcript was only detected in haplotype A $(n=16 / 514)$ (Fig. 1c and d). These results indicated that the expression patterns between haplotypes $\mathrm{A}$ and $\mathrm{B}$ were different.

\section{The expression level and membrane localization were different between haplotypes $a$ and $B$ of the CD4 protein} To further explore the expression pattern of the CD4 gene between haplotypes $\mathrm{A}$ and $\mathrm{B}$, the translation level of the CD4 gene was assessed in vitro. First, the CD4GFP fusion protein vector was constructed. CD4-A-GFP and CD4-B-GFP fusion vectors were obtained by inserting the CDS regions of haplotypes $\mathrm{A}$ or $\mathrm{B}$ into pEGFP$\mathrm{n} 1$ vectors, respectively. These two vectors were transfected into 3D4/21 cell lines. The fluorescence of GFP and the CD4 protein was detected by confocal microscopy at $24 \mathrm{~h}$ and $48 \mathrm{~h}$ post-transfection. The results 


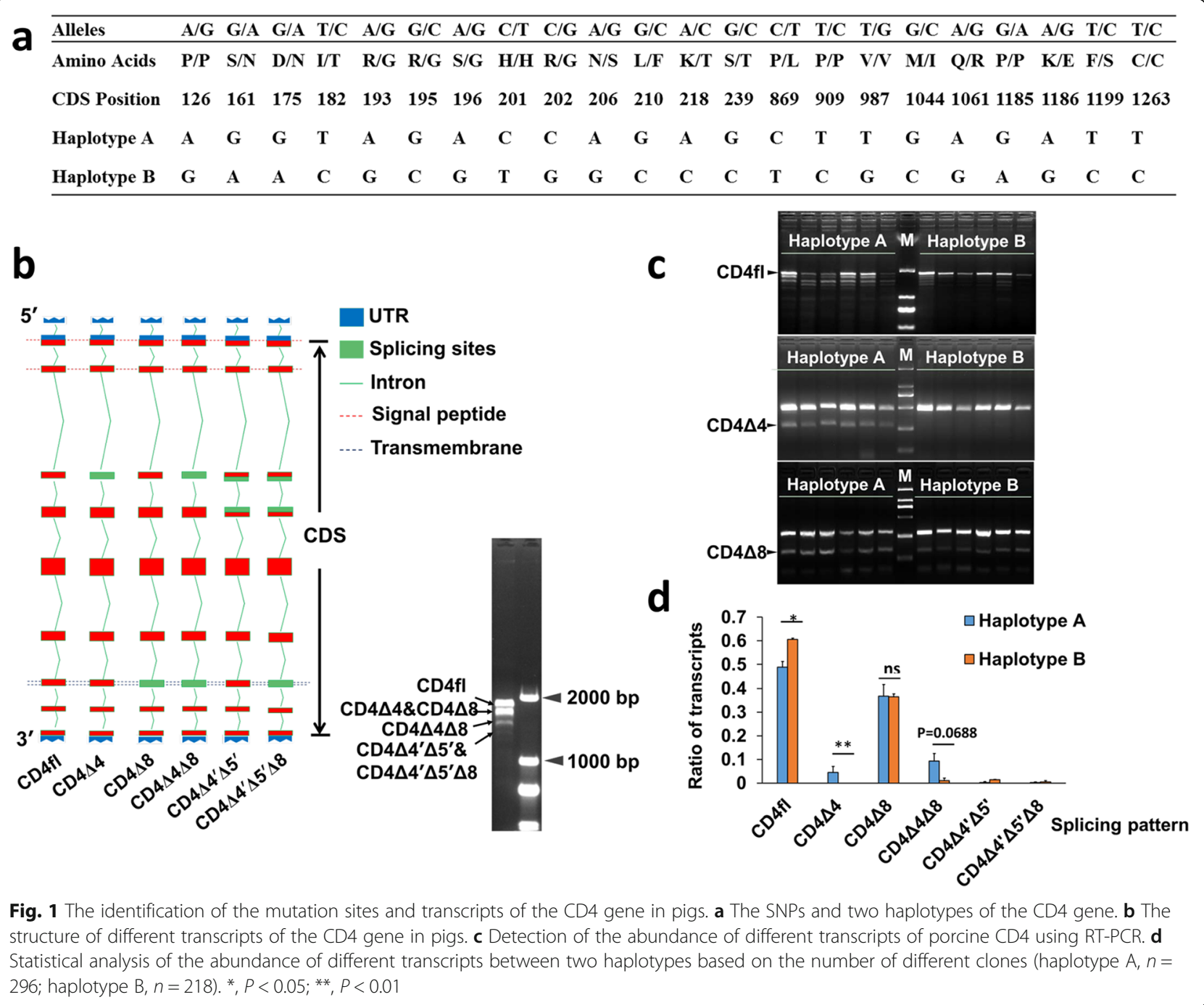

showed that the GFP fluorescence signal in haplotype A was localized mainly in the cytoplasm, but the signal was observed primarily on the cell membrane in haplotype B. The fluorescence signal intensity of GFP in haplotype B was apparently stronger than that in haplotype A, especially at $48 \mathrm{~h}$ post-transfection. Moreover, immunofluorescence results showed that the fluorescence signal of the CD4 antibody was only detected in haplotype B (Fig. 2a).

Furthermore, the expression level of the CD4-GFP fusion protein was detected using a GFP antibody. The western blotting result showed that the expression level of the CD4-GFP fusion protein in haplotype B was obviously higher than that in haplotype A at both $24 \mathrm{~h}$ and $48 \mathrm{~h}$ post-transfection, and the protein levels of both haplotypes $A$ and $B$ at $24 \mathrm{~h}$ were higher than at $48 \mathrm{~h}$ post-transfection (Fig. 2b). Moreover, the CD4-A-flag and CD4-B-flag vectors were also constructed. The expression level of the CD4-Flag fusion protein was detected using a Flag antibody, and the results were consistent with those using CD4-GFP fusion vectors (Fig. S1). These results indicated that the protein level and membrane localization of the $\mathrm{CD} 4$ protein were different between haplotypes A and B.

\section{Pigs with genotypes $A A$ and $B B$ differed in their immune} responses

To study the functional differences between haplotypes $\mathrm{A}$ and $\mathrm{B}$, the peripheral white blood cells from $10 \mathrm{AA}$ and $16 \mathrm{BB}$ pigs were selected for Affymetrix array analysis. According to the result, 180 differentially expressed genes (DEGs) were identified (FC $\geq 1.5, P<0.05$ ). Among them, 128 genes were up-regulated and 52 genes were down-regulated in pigs with genotype AA compared with genotype BB. The top 20 up- and down-regulated genes in genotype AA were listed in Table S1. Pathways were analyzed using the Kyoto Encyclopedia of Genes and Genomes database, and the result revealed that 


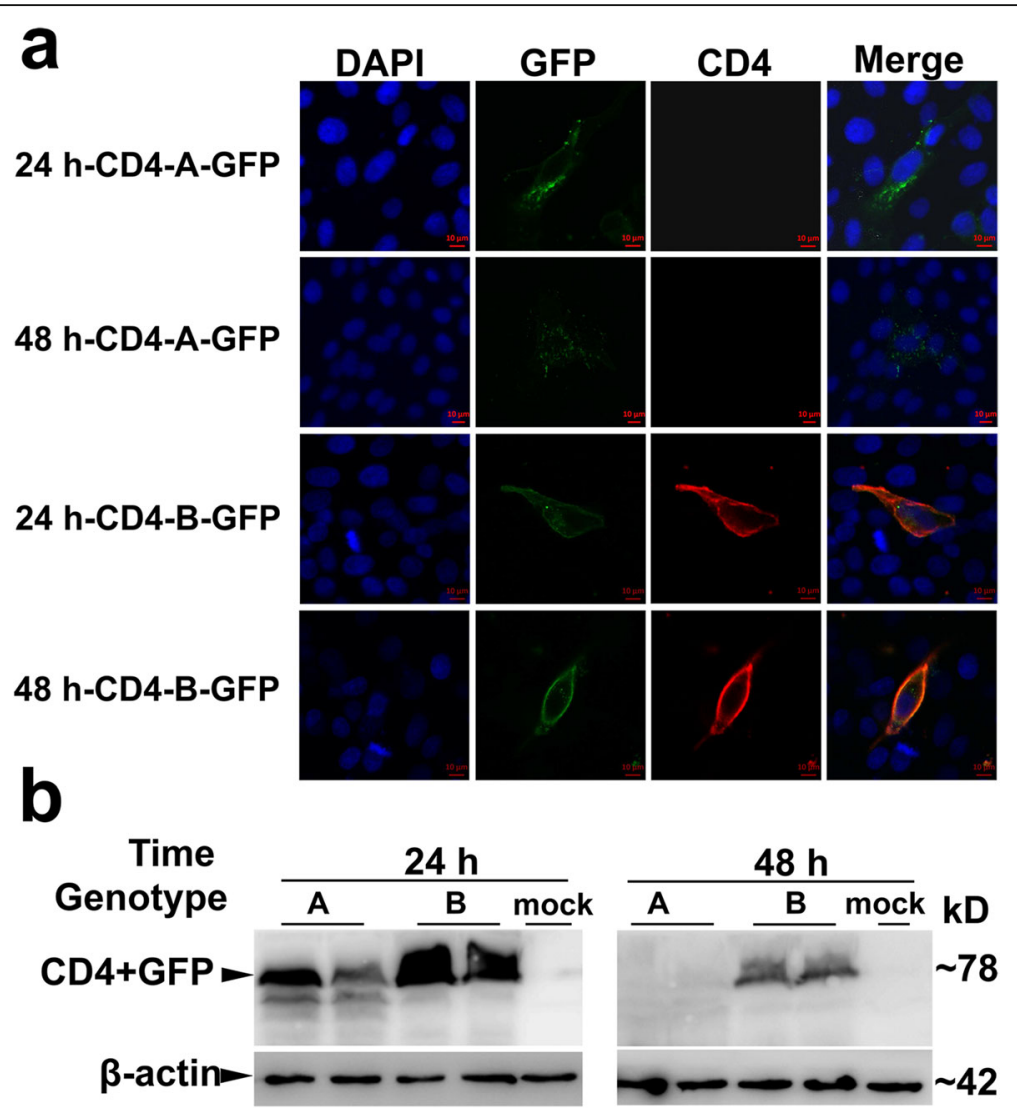

Fig. 2 The expression pattern of the CD4 protein between two haplotypes in pigs. a Confocal images of the immune stain of GFP (green) and CD4 (red) proteins. Nucleus was stained with DAPI (blue). Scale bars: $10 \mu \mathrm{m}$. b Western blotting results of the CD4-GFP fusion protein at $24 \mathrm{~h}$ and $48 \mathrm{~h}$ post-transfection using GFP antibody. $\beta$-actin was used as internal control

most significant enrichment pathways were related to immune responses, which included Salmonella infection, TNF, Toll-like receptor, NF-kB, etc. (Fig. 3a). Furthermore, 12 DEGs related to immune response were selected for further validation through Q-PCR (genotype AA: $n=6$, genotype BB: $n=6$ ) (Fig. $3 \mathrm{~b}$ ), which included eight up-regulated genes (CD14, S100A8, Tnfa, Il18, Il1b1, Il1a, S100A9, and Irf7) and four down-regulated genes (Il1r1, Socs3, Nktr, and Abca1). The Q-PCR results were positively correlated with the Affymetrix array results. The protein interaction network of DEGs was also analyzed using STRING and Cytoscape software. Almost all of the cytokines related to immune responses were up-regulated in genotype BB. However, cytokine signaling suppressors, such as SOCS3, were down-regulated in genotype BB (Fig. 3c). Moreover, western blotting analysis was performed using CD4 antibody and p65 antibody. The result showed that the protein level of phosphorylated p65, which was the activated subunit of NF-kappa B, was lower in genotype AA $(n=5)$ than in $\mathrm{BB}(\mathrm{n}=5)$ (Fig. 3d). These results indicated that the function of the $C D 4$ gene in immune responses was different between genotypes AA and BB.
Three functional mutations determined the functional differences between haplotypes a and B

To explore the specific SNP sites that affected functional differences between haplotypes $\mathrm{A}$ and $\mathrm{B}$, the functional mutations in the CD4 gene were identified. First, the 22 SNPs were divided into three clusters, called cluster 1 (1st-7th SNPs), cluster 2 (8th-13th SNPs), and cluster 3 (14th-22nd SNPs). Six chimeras of haplotypes A and B were constructed, named as $\mathrm{AAB}, \mathrm{BBA}, \mathrm{ABA}, \mathrm{BAB}$, $\mathrm{ABB}$, and BAA (Fig. 4a). These six chimeras were inserted into the pEGFP-n1 vector and then transfected into 3D4/21 cell lines. Subsequently, the fluorescence signal and expression level of the GFP protein were detected at $24 \mathrm{~h}$ and $48 \mathrm{~h}$ post-transfection. Immunofluorescence results showed that the AAB chimera had an expression pattern similar to CD4-A-GFP, whereas the other chimeras were similar to CD4-B-GFP (Fig. 4b). Western blotting results also showed that the expression level of AAB was comparable with CD4-A-GFP, but was lower than that of the other five chimeras and CD4-BGFP (Fig. 4c). Based on these results, we speculated that the key functional mutations were located in the regions of cluster 1 and cluster 2 . 


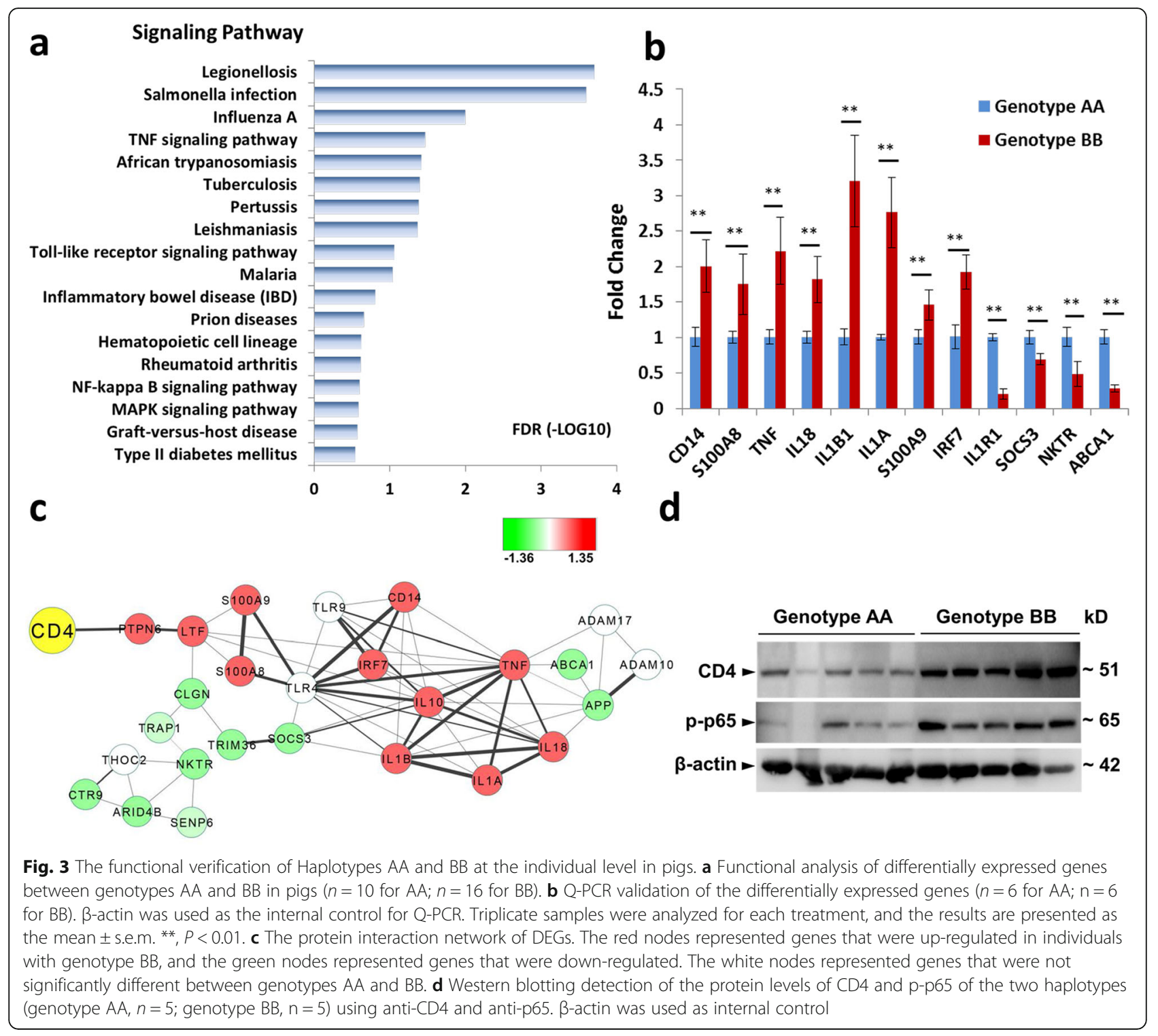

Furthermore, the specific SNPs in cluster 1 and cluster 2 were studied by constructing a series of mutation vectors. First, the two adjacent SNPs (7th and 8th) were mutated (from AC in A to GT in B, involved two amino acids, and marked in red in Fig. 5a), and the mutation was named "Mut 1". Second, five SNPs (from the 5th to the 9th) were mutated from AGACC in haplotype A to GCGTG in haplotype B (involved four amino acids, and marked in red in Fig. 5a), and the mutation was named "Mut 2". Furthermore, seven (from the 4th to the 10th, involved six amino acids, and marked in red in Fig. 5a), nine (from the 3rd to the 11th, eight amino acids, and marked in red in Fig. 5a), and 11 (from the 2nd to the 12th, ten amino acids, and marked in red in Fig. 5a) SNPs were mutated from haplotype A to B, and the mutations were named "Mut 3, Mut 4, and Mut 5", respectively (Fig. 5a). These mutant vectors were transfected into 3D4/21 cell lines. Then, the fluorescence signal and expression level of the GFP protein were detected at $24 \mathrm{~h}$ and $48 \mathrm{~h}$ post-transfection. Immunofluorescence results showed that CD4 proteins were localized in the cytoplasm in cells transfected with Mut1 or haplotype $\mathrm{A}$ at $24 \mathrm{~h}$ and $48 \mathrm{~h}$ post-transfection. The expression pattern and localization of the $\mathrm{CD} 4$ protein in cells transfected with other mutational constructs were similar to that of haplotype B both at $24 \mathrm{~h}$ and $48 \mathrm{~h}$ (Fig. 5b). Western blot results indicated that the CD4 protein level in cells transfected with Mut1 was similar to haplotype A, but lower than that of haplotype B and other mutational constructs (Fig. 5c).

Moreover, the specific bases of haplotype B were also mutated to that of haplotype $\mathrm{A}$, and the mutations were 

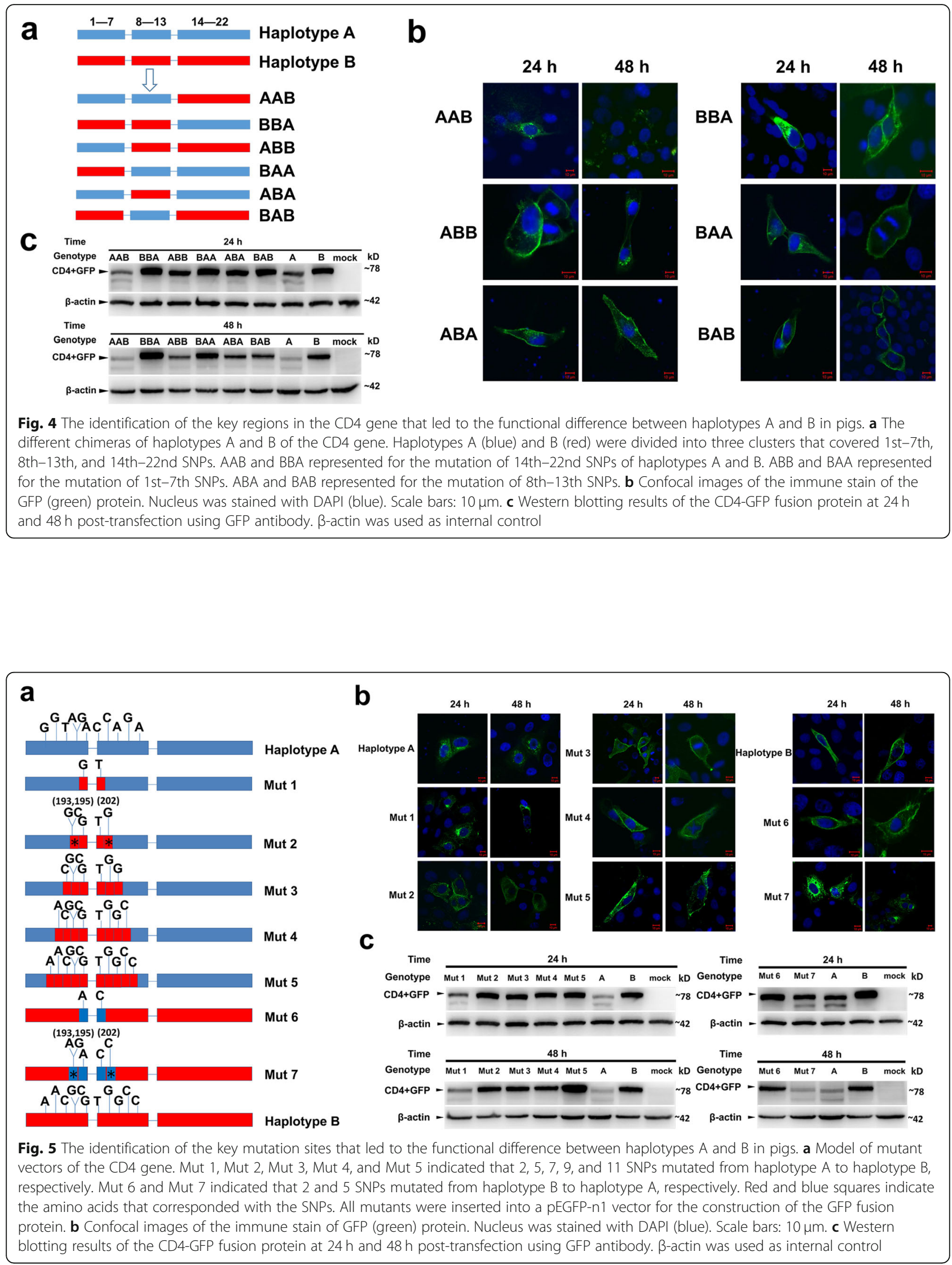
named "Mut 6" (GT to AC at the 7th and 8th sites that involved two amino acids, and mutation sites were marked in blue) and "Mut 7" (GCGTG to ACACC from the 5th to the 9th sites that involved two amino acids, and the mutation sites were marked in blue)". Immunofluorescence results showed that the CD4 protein in cells transfected with Mut 6 were localized on cell membranes, which was similar to haplotype B, but the CD4 protein in cells transfected with Mut 7 mainly localized in the cytoplasm, which was similar to haplotype A (Fig. $5 b)$. Western blotting results showed that the protein expression level of the $\mathrm{CD} 4$ protein in cells transfected with Mut 6 was comparable with haplotype B, but it was much higher than that of haplotype A and Mut 7, especially at $48 \mathrm{~h}$ post-transfection (Fig. $5 \mathrm{c}$ ). These results indicated that the 193A/G SNPs, 195G/C SNPs, and 202C/G SNPs in the CDS region could influence the expression level and membrane localization of the CD4 protein.

In addition, 193A/G SNPs, 195G/C SNPs, and 202C/G SNPs were further considered. These three SNPs were mutated one by one, and the results showed that all of them affected the expression level and localization of the CD4 protein (Fig. S2). In addition, we found that these three SNPs led to the replacement of 65th and 68th amino acids in the CD4 protein, and these two amino acids were localized at the IgV1 domain (Fig. 6a). Therefore, these three SNPs (193A/G, 195G/C, and 202C/G, which involved 65R/G and 68R/G amino acids replacement) were important for the expression pattern and function in the immune response of the $\mathrm{CD} 4$ protein.

\section{The distribution of a and B alleles was different among pig breeds}

This study further investigated the distribution of $\mathrm{A}$ and $\mathrm{B}$ alleles in different pig breeds. Bases on the mutation results, the 193A/G SNP, 195G/C SNP, and 202C/G SNP affected the expression and function between different haplotypes of the $C D 4$ gene. Therefore, the distribution of these three linked SNPs was researched in four group of pig breeds, which included ten Chinese indigenous breeds $(n=334)$, four western commercial breeds $(n=312)$, one European wild boar population $(n=47)$, and one Asian wild boar population $(n=40)$. The result showed that the frequency of allele A in Chinese breeds $(\mathrm{q}=0.445)$ was higher than in western commercial breeds $(q=0.008)$, the European wild boar population $(\mathrm{q}=0)$, or the Asian wild boar population $(\mathrm{q}=0.088)$ (Table 1), while the distribution of allele $\mathrm{B}$ was just the opposite.

\section{Discussion}

The CD4 protein was confirmed to play an important role in the development of $\mathrm{T}$ cells and the immune response [19], and the CD4 gene was an important candidate for immune-related diseases in humans and pigs $[13,20,21]$. The $C D 4$ gene interacted with the $M H C$ gene, and both of them were rich in SNP sites [22]. Previous studies mentioned that immune-related genes were rich in SNPs, and they could be beneficial for adaptive immune responses by the host [23-25].

In this study, 22 SNPs were found in the CDS region of the CD4 gene, which led to the conversion of amino acids and the formation of two haplotypes. Matsubara et al. also divided the $C D 4$ gene into two haplotypes in miniature pigs by SNP analysis, but it is different from the SNPs screened out in this study [18]. Furthermore, we investigated the functional differences between the two haplotypes. Interestingly, there was no significant difference at the transcription level between haplotypes A and B (Fig. S3), but the translation level was significant difference in vitro and in vivo. Therefore, we postulated that the post-transcription regulation mainly caused the protein level difference between the two haplotypes.

The CD4 protein participated in the representation of antigen through interaction with the MHCII molecule and played an important role in the immune response [19]. In this study, we found that the expression level of the $\mathrm{CD} 4$ protein was significantly different between haplotypes A and B. We suspected that this led to differences in the immune response in pigs. As expected, transcriptome analysis indicated that most of the DEGs were enriched in inflammatory and immune-related pathways, which included the TLR, TNF, and NF- $k B$ classic immune regulatory signaling pathways. Moreover, most cytokines related to immune responses were down-regulated in genotype AA. Furthermore, TNF $\alpha$, IL1B1, and TLR4 were the center nodes in the analysis of protein interaction network, and the expression levels of Tnfa and Illb1 genes were significantly lower in haplotype A than in haplotype B. Moreover, western blotting results showed that the expression level of phosphorylated p65 was down-regulated in genotype AA. It is known that phosphorylated p65 could positively regulate TNF $\alpha$ and IL1B1 at the transcriptional level $[26,27]$. These results indicated that there were significant differences between the two haplotypes of the $C D 4$ gene in the immune response.

This study demonstrated that the formation of two haplotypes of the $C D 4$ gene was due to the existence of 22 fully linked SNPs in the CDS region, among which three key sites determined the functional conversion between haplotypes A and B. In addition, these three linked SNPs led to the mutation of two amino acids in the IgV1 domain of the CD4 protein (Fig. 6a), which is a domain that was very important for the function of the CD4 protein in the immune response [28]. IgV1 was the 

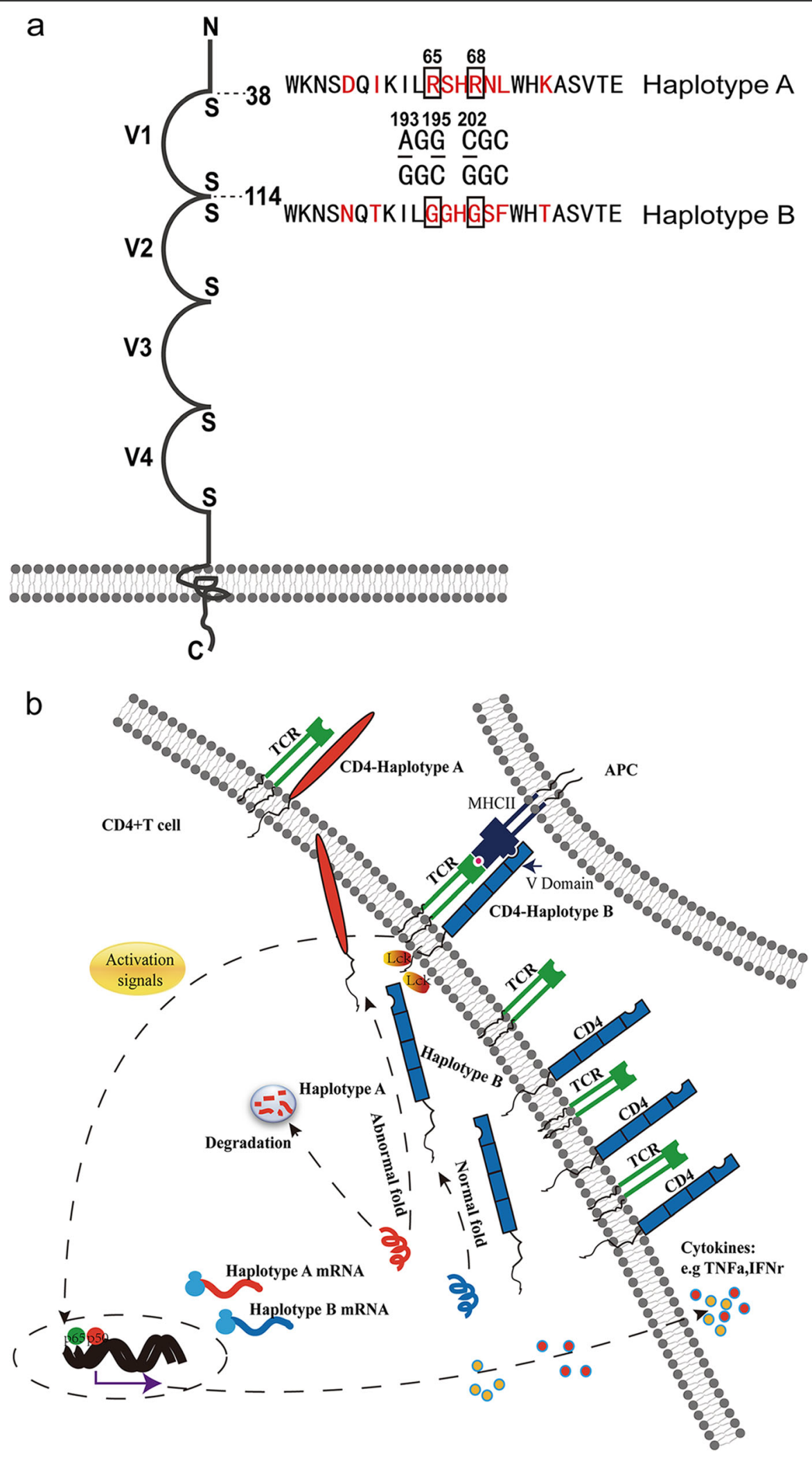

Fig. 6 (See legend on next page.) 
(See figure on previous page.)

Fig. 6 The localization of two key amino acids and the schema graph of the function of CD4 protein in the immune response of T cells. a The structure of the CD4 protein domain in pigs, which included four extracellular domains, one trans-membrane domain, and one intercellular domain. The three key SNPs (193A/G, 195G/C, and 202C/G) led to two amino acid conversions (65R/G and 68R/G), and these two amino acids were in the IgV1 domain. $\mathbf{b}$ The schema graph of the function of the CD4 protein in the immune response

key domain in the binding of CD4 protein to MHCII $[29,30]$ and to gp120 [7, 31, 32]. Therefore, we hypothesized that the IgV1 domain of the CD4 protein in haplotype A was dysfunctional, which led to the enhanced degradation of the $\mathrm{CD} 4$ protein. However, the CD4 protein of haplotype $\mathrm{B}$ had a fully functional structural domain, which transmitted the activation signal from antigen presenting cells (APC) to T cells that stimulated the release of immune response factors by activating the expression of p65 (Fig. 6b).

In addition, we found that the distribution of alleles $\mathrm{A}$ and $\mathrm{B}$ was different among different pig breeds. The CD4 gene appeared as allele $\mathrm{B}$ in almost all western commercial pigs and wild pigs, and as allele $\mathrm{A}$ in about $50 \%$ of Chinese domestic pigs. We believe that Chinese domestic pigs experienced a selection process that resulted in an increase in the frequency of allele A. The CD4 gene may be one of the candidates for this difference. Previous studies confirmed that Chinese indigenous breeds had different immune responses compared with western commercial pigs due to a selection sweep [33, 34]. Interestingly, we found a small number of $A B$ heterozygotes in Large White pigs (Table 1). During breeding, Chinese pigs were used for Large White breed cultivation [34]. Thus, we suspected that allele A in the
Large White pig breed originated from Chinese pig breeds.

\section{Conclusion}

Combining these results, we concluded that the difference in the immune response between haplotypes $\mathrm{A}$ and B was due to the presence of three SNPs (193A/G, $195 \mathrm{G} / \mathrm{C}$, and $202 \mathrm{C} / \mathrm{G}$ ) in the CDS region of the CD4 gene. Further, these three SNPs may be used for animal breeding or as therapeutic targets of immune-related diseases.

\section{Methods \\ Cells and samples}

The white blood cells were obtained from the F2 population of Duroc $\times$ Erhualian. The total RNA, DNA, and protein used in this study were extracted from the white blood cells. 3D4/21 cells were bought from ATCC (https://www.atcc.org/). DNA used for allele frequency analysis was stored in our lab.

\section{Transcriptome and functional analysis of the differentially expressed genes}

Gene expression patterns of white blood cells were detected by using Affymetrix GeneChip. Haplotype AA

Table 1 Allele distribution of the three linked functional mutations in different breeds of pigs

\begin{tabular}{|c|c|c|c|c|c|c|c|}
\hline \multirow[t]{2}{*}{ Population } & \multirow[t]{2}{*}{ Breed } & \multirow[t]{2}{*}{ Number } & \multicolumn{3}{|c|}{ Genotype } & \multirow{2}{*}{$\begin{array}{l}\text { Allele A } \\
\text { frequency }\end{array}$} & \multirow{2}{*}{$\begin{array}{l}\text { Allele B } \\
\text { frequency }\end{array}$} \\
\hline & & & AA & $A B$ & BB & & \\
\hline \multirow[t]{10}{*}{ Chinese breeds } & Erhualian & 17 & 10 & 7 & 0 & \multirow[t]{10}{*}{0.445} & \multirow[t]{10}{*}{0.555} \\
\hline & Luchuan & 55 & 34 & 21 & 0 & & \\
\hline & Longlin & 39 & 8 & 13 & 18 & & \\
\hline & Dongshan & 22 & 0 & 8 & 14 & & \\
\hline & Xiaomeishan & 11 & 5 & 6 & 0 & & \\
\hline & Wuzhishan & 14 & 6 & 6 & 2 & & \\
\hline & Dahuabai & 17 & 8 & 7 & 2 & & \\
\hline & Lantang & 12 & 2 & 9 & 1 & & \\
\hline & Enshi Black & 69 & 8 & 40 & 21 & & \\
\hline & Tongcheng & 78 & 0 & 18 & 60 & & \\
\hline \multirow[t]{4}{*}{ Western breeds } & Duroc & 34 & 0 & 0 & 34 & \multirow[t]{4}{*}{0.008} & \multirow[t]{4}{*}{0.992} \\
\hline & Large White & 254 & 0 & 5 & 249 & & \\
\hline & Landrace & 16 & 0 & 0 & 16 & & \\
\hline & Pietrain & 8 & 0 & 0 & 8 & & \\
\hline European wild boar & & 47 & 0 & 0 & 47 & 0 & 1 \\
\hline Asian wild boar & & 40 & 1 & 5 & 34 & 0.088 & 0.912 \\
\hline
\end{tabular}


$(n=10)$ and $\mathrm{BB}$ individuals $(n=16)$ were selected for analysis of differentially expressed genes. The details of the analysis were shown in our previous studies $[35,36]$. Briefly, all raw probe-level microarray data were normalized by the Robust Multichip Average method with the bioconductor AFFY package (www.bioconductor.org). The differentially expressed genes $(P<0.05, \mathrm{FC} \geq 1.5)$ were identified using the LIMMA tool. Two-way hierarchical clustering analysis was performed after identifying the differentially expressed genes. The signaling pathways of differentially expressed genes were analyzed using DAVID tools (https://david.ncifcrf.gov/). The interaction of the differentially expressed genes was analyzed using STRING (https://string-db.org/) and the network figure was drawn using Cytoscape 3.5.1 (http:// www.cytoscape.org/).

\section{Identification of the transcripts}

The RNA of three individuals with genotype $A B$ of the CD4 gene was extracted. RT-PCR was performed to amplify the exon regions of the $C D 4$ gene. The reverse transcription PCR (RT-PCR) products contained the full length coding regions and partial $3^{\prime}$ - and $5^{\prime}$-UTR regions of the $C D 4$ gene. The products were cloned in the pMD-19 T vector and transfected into E. coli DH5 $\alpha$. A total of 514 clones were sequenced. The different transcripts of the CD4 gene and their frequencies were calculated. A T-test was used for significance analysis. The primers used for RT-PCR are listed in Table S2.

\section{Quantitative PCR (Q-PCR)}

The RNA in peripheral white blood cells of F2 pigs with genotype AA $(n=6)$ and $\mathrm{BB}(n=6)$ were selected randomly for Q-PCR analysis. The quality of total RNA was assessed using Nano Drop2000 (ThermoFisher Scientific, Waltham, MA, USA). In brief, $1 \mu \mathrm{g}$ of the RNA of each sample was used to synthesize cDNA using a PrimeScript $^{\mathrm{TM}}$ RT reagent Kit with gDNA Eraser (Takara, Tokyo, Japan). THUNDERBIRD SYBR qPCR Mix (TOYOBO, Japan) was used for Q-PCR, and the results were monitored using a CFX384 Real-Time PCR Detection System (Bio-Rad, USA). The primers are listed in Table S3. T-test was used for statistical analysis.

\section{Construction of expression vectors, cell culture, and transfection}

pEGFP-n1 (Clontech, USA) and pCDNA3.1 (Invitrogen, USA) vectors were used to construct CD4-GFP fusion protein and CD4-flag expression vectors (Table S4 and Table S5). The 3D4/21 cell line was stored previously in $7 \%$ dimethyl sulfoxide (DMSO) in our lab. The cells were gently thawed in a $37^{\circ} \mathrm{C}$ water bath, and then DMSO was removed and discarded. The cells were cultured in RPMI 1640 (Gibco, USA) supplemented with
10\% FBS and 1\% MEM NEAA (Gibco, USA) and cultured routinely at $37^{\circ} \mathrm{C}$ with $5 \% \quad \mathrm{CO}_{2}$. For subcultivation, cells were rinsed with $0.25 \%$ trypsin- -0.53 mM EDTA solution. All the constructions were transfected into 3D4/21 cells using Lipofectamine 2000 (Invitrogen, USA) according to the manufacturer's recommendations.

\section{Immunofluorescence}

Cells were seeded on chamber slides. The cells were then fixed for $10 \mathrm{~min}$ in $4 \%$ paraformaldehyde. After fixing, the cells were blocked for $2 \mathrm{~h}$ in 3\% BSA and 10\% FBS. The cells were incubated at $4{ }^{\circ} \mathrm{C}$ overnight with 1 : 100 Phycoerythrin -conjugated Mouse anti-pig CD4a (BD, \#559586, USA) or 1:2000 anti-flag antibody (ABclonal, \#AE005, China). After washing with PBS, the cells were stained with nuclear-specific DAPI stain. After staining, the cells were photographed using a laser scanning confocal microscope (ZEISS, Germany, LSM 510 META).

\section{Western blotting}

3D4/21 cells were plated in six-well culture dishes and transfected with target vectors when they converged to approximately $70 \%$. After $24 \mathrm{~h}$ and $48 \mathrm{~h}$, the total proteins in the cells were extracted using RIPA buffer (Thermo Fisher Scientific, New York, USA, \#89900). The proteins were diluted in SDS loading buffer and then heated for $10 \mathrm{~min}$ at $100{ }^{\circ} \mathrm{C}$ for denaturation. The proteins were electrophoresed through $12 \%$ SDS-PAGE and then transferred to a nitrocellulose filter. Membranes were blocked in 5\% non-fat milk for $1 \mathrm{~h}$ at room temperature and incubated with 1:1000 anti-GFP antibody (ABclonal, AE012), 1:2000 anti-flag antibody (ABclonal, AE005), 1:1000 anti-CD4 antibody (Abcam, UK, 25804), 1:1000 anti- $\beta$-actin antibody (Beyotime, Shanghai, China, AF0003), or 1:1000 anti-p-p65 antibody (CST, USA, 4025) at $4{ }^{\circ} \mathrm{C}$ overnight. Membranes were incubated with 1:1000 horseradish peroxidase-labeled anti-rabbit-IgG secondary antibody (Beyotime, Shanghai, China, A0208) or anti-mouse-IgG secondary antibody (Beyotime, Shanghai, China, A0216) for $1 \mathrm{~h}$ at room temperature. Immunodetection was performed by an Image Quant LAS4000 mini (GE, USA). The gray values of the protein bands were measured using ImageQuantTL software (GE, USA), and $\beta$-actin protein levels were used as internal control.

\section{Supplementary Information}

The online version contains supplementary material available at https://doi. org/10.1186/s12860-020-00333-7.

Additional file 1: Figure S1. The expression pattern of the CD4 protein in two haplotypes using a PCDNA3.1 + -CD4-flag fusion vector. 
Additional file 2: Figure S2. The identification of the key mutation sites that led to the functional difference between haplotypes A and B.

Additional file 3. Q-PCR results of the expression change of the CD4 gene in genotypes $A A$ and $B B$.

Additional file 4: Table S1. Top 20 of up-regulated genes and downregulated genes in pigs with genotype AA.

Additional file 5: Table S2. Primers used for haplotype identification in this study.

Additional file 6: Table S3. Primers used for Q-PCR in this study. Additional file 7: Table S4 Primers used for vector construction in this study.

Additional file 8: Table S5 Primers used for vector construction in this study.

\section{Acknowledgments}

We thank Yunxia Zhao, Yu Luan and Yueyuan Xu for assistance with data analysis, Haoyuan Zhang for sample collection, and Xiaosong Han for experimental assistance.

\section{Authors' contributions}

WZ and JN conducted the experiments and prepared the materials involved in this study. JZ and HW performed the bioinformatics analysis. SZ and XL conceived of this study. SZ, XL, WZ, and JN participated in its design and coordination. XL, WZ, JN, LZ, CZ, and $\mathrm{HZ}$ contributed to the analysis and interpretation of the data. JN drafted the manuscript. SZ, XL, MZ, HW, and JH helped to revise the manuscript. And all authors have read and approved the manuscript.

\section{Funding}

This study was supported by the National Natural Science Foundation of China (31941008, 31672392) and the Fund of Modern Industrial Technology System of 552 Pig (CARS-35).

\section{Availability of data and materials}

The datasets used and analyzed during the current study available from the corresponding author on reasonable request.

\section{Ethics approval and consent to participate}

All procedures were performed in accordance with the approved guidelines of Regulation of the Standing Committee of Hubei People's Congress (Wuhan, P.R. China). The experimental protocols were approved by the ethics committee of Huazhong Agricultural University (HZAUMU2013-0005) (Wuhan, P.R. China).

\section{Consent for publication}

Not Applicable.

\section{Competing interests}

The authors declare that they have no competing or financial interests.

\section{Author details}

${ }^{1}$ Mountainous Area Research Institute of Hebei Province, Hebei Agricultural University, No. 289 Lingyusi Street, Lianchi District, Baoding, Hebei Province 071001, P. R. China. ${ }^{2}$ Zhejiang Cancer Research Institute, Hangzhou, China. ${ }^{3}$ Huazhong Agricultural University, No.1 Shizishan Street, Hongshan District, Wuhan, Hubei Province 430070, P. R. China. ${ }^{4}$ Key Laboratory of Agricultural Animal Genetics, Breeding, and Reproduction of the Ministry of Education, Swine Genetics and Breeding of Ministry of Agriculture and Rural Affairs, Huazhong Agricultural University, No.1 Shizishan Street, Hongshan District, Wuhan, Hubei Province 430070, P. R. China. ${ }^{5}$ Livestock Genetics Program, International Livestock Research Institute (ILRI), Nairobi, Kenya. ${ }^{6}$ The Cooperative Innovation Center for Sustainable Pig Production, Wuhan, China.
Received: 7 May 2020 Accepted: 24 November 2020

Published online: 09 December 2020

\section{References}

1. Wood GS, Warner NL, Warnke RA. Anti-Leu-3/T4 antibodies react with cells of monocyte/macrophage and Langerhans lineage. J Immunol. 1983;131(1): 212-6.

2. Lynch GW, Turville S, Carter B, Sloane AJ, Chan A, Muljadi N, Li S, Low L, Armati $\mathrm{P}$, Raison $\mathrm{R}$, et al. Marked differences in the structures and protein associations of lymphocyte and monocyte CD4: resolution of a novel CD4 isoform. Immunol Cell Biol. 2006:84(2):154-65.

3. Bosselut R. CD4/CD8-lineage differentiation in the thymus: from nuclear effectors to membrane signals. Nat Rev Immunol. 2004:4(7):529-40.

4. Tian Y, Sette A, Weiskopf D. Cytotoxic CD4 T cells: differentiation, function, and application to dengue virus infection. Front Immunol. 2016;7:531.

5. Wang JH, Yan YW, Garrett TP, Liu JH, Rodgers DW, Garlick RL, Tarr GE, Husain Y, Reinherz EL, Harrison SC. Atomic structure of a fragment of human CD4 containing two immunoglobulin-like domains. Nature. 1990; 348(6300):411-8.

6. Lange G, Lewis SJ, Murshudov GN, Dodson GG, Moody PC, Turkenburg JP, Barclay AN, Brady RL. Crystal structure of an extracellular fragment of the rat CD4 receptor containing domains 3 and 4. Structure. 1994;2(6):469-81.

7. Sharma D, Balamurali MM, Chakraborty K, Kumaran S, Jeganathan S, Rashid $U$, Ingallinella P, Varadarajan R. Protein minimization of the gp120 binding region of human CD4. Biochemistry. 2005;44(49):16192-202.

8. Issuree PD, $\mathrm{Ng}$ CP, Littman DR. Heritable gene regulation in the CD4:CD8 T cell lineage choice. Front Immunol. 2017:8:291.

9. Steinke FC, Yu S, Zhou X, He B, Yang W, Zhou B, Kawamoto H, Zhu J, Tan K, Xue HH. TCF-1 and LEF-1 act upstream of Th-POK to promote the CD4(+) T cell fate and interact with Runx3 to silence Cd4 in CD8(+) T cells. Nat Immunol. 2014;15(7):646-56.

10. Locksley RM, Reiner SL, Hatam F, Littman DR, Killeen N. Helper T cells without CD4: control of leishmaniasis in CD4-deficient mice. Science. 1993; 261(5127):1448-51.

11. Feito MJ, Ballester S, Diez-Orejas R, Ojeda G, Criado G, Portoles P, Rojo JM CD4 dependence of activation threshold and TCR signalling in mouse T Iymphocytes. Scand J Immunol. 1997:45(2):166-74.

12. Kristiansen $O P$, Karlsen AE, Larsen ZM, Johannesen J, Pociot F, MandrupPoulsen T, Danish IE, Genetics G, Danish study group of liC. Identification of a type 1 diabetes-associated CD4 promoter haplotype with high constitutive activity. Scand J Immunol. 2004;59(6):582-91.

13. Hussein YM, El Tarhouny SA, Mohamed RH, El-Shal AS, Abul-Saoud AM, Abdo M. Association of CD4 enhancer gene polymorphisms with rheumatoid arthritis in Egyptian female patients. Rheumatol Int. 2012;32(8): 2325-30.

14. Oyugi JO, Vouriot FC, Alimonti J, Wayne S, Luo M, Land AM, Ao Z, Yao X, Sekaly RP, Elliott $L$, et al. A common CD4 gene variant is associated with an increased risk of HIV-1 infection in Kenyan female commercial sex workers. J Infect Dis. 2009;199(9):1327-34

15. Lu Y, Wu J, Qin X, Xie L, Ma L, Huang X, Zhao J, Liu Y, Chen X, Li S. The CD4 C868T polymorphism and its correlation with HIV-1 infection in a Chinese population. AIDS Res Hum Retrovir. 2015;31(5):525-30.

16. Choi RY, Farquhar C, Juno J, Mbori-Ngacha D, Lohman-Payne B, Vouriot F, Wayne S, Tuff J, Bosire R, John-Stewart G, et al. Infant CD4 C868T polymorphism is associated with increased human immunodeficiency virus (HIV-1) acquisition. Clin Exp Immunol. 2010;160(3):461-5.

17. Humes D, Emery S, Laws E, Overbaugh J. A species-specific amino acid difference in the macaque CD4 receptor restricts replication by global circulating HIV-1 variants representing viruses from recent infection. J Virol. 2012;86(23):12472-83.

18. Matsubara T, Nishii N, Takashima S, Takasu M, Imaeda N, Aiki-Oshimo K, Yamazoe K, Kakisaka M, Takeshima SN, Aida Y, et al. Identification and characterization of two CD4 alleles in Microminipigs. BMC Vet Res. 2016; 12(1):222

19. Corbishley A, Connelley TK, Wolfson EB, Ballingall K, Beckett AE, Gally DL, McNeilly TN. Identification of epitopes recognised by mucosal CD4(+) T-cell populations from cattle experimentally colonised with Escherichia coli 0157 H7. Vet Res. 2016;47(1):90.

20. Vaughan AN, Malde P, Rogers NJ, Jackson IM, Lechler Rl, Dorling A. Porcine CTLA4-lg lacks a MYPPPY motif, binds inefficiently to human B7 and 
specifically suppresses human CD4+ T cell responses costimulated by pig but not human B7. J Immunol. 2000;165(6):3175-81.

21. Annamalai T, Saif $L$, Lu Z, Jung K. Age-dependent variation in innate immune responses to porcine epidemic diarrhea virus infection in suckling versus weaned pigs. Vet Immunol Immunopathol. 2015;168(3-4):193-202.

22. Hosomichi K, Miller MM, Goto RM, Wang Y, Suzuki S, Kulski JK, Nishibori M, Inoko H, Hanzawa K, Shiina T. Contribution of mutation, recombination, and gene conversion to chicken MHC-B haplotype diversity. J Immunol. 2008; 181(5):3393-9.

23. Li C, He H, Liu A, Liu H, Huang H, Zhao C, Jing L, Ni J, Yin L, Hu S, et al. Natural functional SNPs in miR-155 Alter its expression level, blood cell counts, and immune responses. Front Immunol. 2016;7:295.

24. Potts WK, Slev PR. Pathogen-based models favoring MHC genetic diversity. Immunol Rev. 1995;143:181-97.

25. Sommer $\mathrm{S}$. The importance of immune gene variability $(\mathrm{MHC})$ in evolutionary ecology and conservation. Front Zool. 2005;2:16.

26. Bonizzi G, Karin M. The two NF-kappaB activation pathways and their role in innate and adaptive immunity. Trends Immunol. 2004;25(6):280-8.

27. Lee SI, Kim HS, Koo JM, Kim IH. Lactobacillus acidophilus modulates inflammatory activity by regulating the TLR4 and NF-kappaB expression in porcine peripheral blood mononuclear cells after lipopolysaccharide challenge. Br J Nutr. 2016;115(4):567-75.

28. Piatier-Tonneau D, Gastinel LN, Moussy G, Benichou B, Amblard F, Vaigot P, Auffray C. Mutations in the D strand of the human CD4 V1 domain affect CD4 interactions with the human immunodeficiency virus envelope glycoprotein gp120 and HLA class II antigens similarly. Proc Natl Acad Sci U S A. 1991;88(15):6858-62.

29. Meuer SC, Schlossman SF, Reinherz EL. Clonal analysis of human cytotoxic T lymphocytes: T4+ and T8+ effector T cells recognize products of different major histocompatibility complex regions. Proc Natl Acad Sci U S A. 1982; 79(14):4395-9

30. Wang JH, Meijers R, Xiong Y, Liu JH, Sakihama T, Zhang R, Joachimiak A, Reinherz EL. Crystal structure of the human CD4 N-terminal two-domain fragment complexed to a class II MHC molecule. Proc Natl Acad Sci U S A. 2001;98(19):10799-804.

31. Kwong PD, Wyatt R, Robinson J, Sweet RW, Sodroski J, Hendrickson WA. Structure of an HIV gp120 envelope glycoprotein in complex with the CD4 receptor and a neutralizing human antibody. Nature. 1998;393(6686):648-59.

32. Ryu SE, Kwong PD, Truneh A, Porter TG, Arthos J, Rosenberg M, Dai XP, Xuong NH, Axel R, Sweet RW, et al. Crystal structure of an HIV-binding recombinant fragment of human CD4. Nature. 1990;348(6300):419-26.

33. Li XL, Yang SB, Tang ZL, Li K, Liu B, Fan B. Genome-wide selective sweep analysis on large white and Tongcheng pigs. Yi Chuan. 2012;34(10):1271-81.

34. Li X, Yang S, Tang Z, Li K, Rothschild MF, Liu B, Fan B. Genome-wide scans to detect positive selection in large white and Tongcheng pigs. Anim Genet. 2014;45(3):329-39.

35. Liu X, Huang J, Yang S, Zhao Y, Xiang A, Cao J, Fan B, Wu Z, Zhao J, Zhao S, et al. Whole blood transcriptome comparison of pigs with extreme production of in vivo dsRNA-induced serum IFN-a. Dev Comp Immunol. 2014:44(1):35-43.

36. Wang H, Hou Y, Guo J, Chen H, Liu X, Wu Z, Zhao S, Zhu M. Transcriptomic landscape for lymphocyte count variation in poly l:C-induced porcine peripheral blood. Anim Genet. 2016;47(1):49-61.

\section{Publisher's Note}

Springer Nature remains neutral with regard to jurisdictional claims in published maps and institutional affiliations.

Ready to submit your research? Choose BMC and benefit from:
- fast, convenient online submission
- thorough peer review by experienced researchers in your field
- rapid publication on acceptance
- support for research data, including large and complex data types
- gold Open Access which fosters wider collaboration and increased citations
- maximum visibility for your research: over 100M website views per year
At BMC, research is always in progress.
Learn more biomedcentral.com/submissions

